\title{
Spine impairment in mice high-expressing neuregulin 1 due to LIMK1 activation
}

\author{
Peng Chen ${ }^{1,2}$, Hongyang Jing ${ }^{1,2}$, Mingtao Xiong ${ }^{2}$, Qian Zhang ${ }^{3}$, Dong Lin 1,2, Dongyan Ren ${ }^{1,2}$, Shunqi Wang ${ }^{1,2}$, \\ Dongmin Yin $\mathbb{1}^{4}$, Yongjun Chen ${ }^{5}$, Tian Zhou ${ }^{3}$, Baoming $\mathrm{Li}^{2}$, Erkang Fei ${ }^{1,2}$ and Bing-Xing Pan ${ }^{1,2}$
}

\begin{abstract}
The genes encoding for neuregulin1 (NRG1), a growth factor, and its receptor ErbB4 are both risk factors of major depression disorder and schizophrenia (SZ). They have been implicated in neural development and synaptic plasticity. However, exactly how NRG1 variations lead to SZ remains unclear. Indeed, NRG1 levels are increased in postmortem brain tissues of patients with brain disorders. Here, we studied the effects of high-level NRG1 on dendritic spine development and function. We showed that spine density in the prefrontal cortex and hippocampus was reduced in mice (ctoNrg1) that overexpressed NRG1 in neurons. The frequency of miniature excitatory postsynaptic currents (mEPSCs) was reduced in both brain regions of ctoNrg1 mice. High expression of NRG1 activated LIMK1 and increased cofilin phosphorylation in postsynaptic densities. Spine reduction was attenuated by inhibiting LIMK1 or blocking the NRG1-LIMK1 interaction, or by restoring NRG1 protein level. These results indicate that a normal NRG1 protein level is necessary for spine homeostasis and suggest a pathophysiological mechanism of abnormal spines in relevant brain disorders.
\end{abstract}

\section{Introduction}

Neuregulin1 (NRG1) is a large family of neurotrophic factors produced by mRNA splicing of a single gene. With an EGF-like domain, it binds to and activates ErbB receptors such as ErbB4, to initiate downstream signaling pathways ${ }^{1}$. NRG1 is produced in excitatory neurons, GABAergic interneurons, and astrocytes in the brain ${ }^{2-6}$. During development, ErbB4 is expressed in interneuron precursor cells and NRG1/ErbB4 signaling plays a role in assembling the GABAergic circuitry, including interneuron migration and differentiation such as axon development and the formation of excitatory synapses onto interneurons and inhibitory synapses onto pyramidal neurons ${ }^{6-10}$. In adult animals, ErbB4 is almost exclusively in GAD + (glutamate decarboxylase positive)

\footnotetext{
Correspondence: Erkang Fei (fek@ncu.edu.cn) or

Bing-Xing Pan (panbingxing@ncu.edu.cn)

${ }^{1}$ School of Life Sciences, Nanchang University, Nanchang 330031, China ${ }^{2}$ Institute of Life Science, Nanchang University, Nanchang 330031, China

Full list of author information is available at the end of the article

These authors contributed equally: Peng Chen, Hongyang Jing

Edited by A. Sawa
}

interneurons in the cerebral cortex, hippocampus (HPF), and amygdala and has been shown critical to GABA ( $\gamma$ aminobutyric acid) release and excitation-inhibition (E-I) balance ${ }^{11-13}$. Besides, ErbB2 and ErbB4 have been implicated in forming excitatory synapses onto pyramidal neurons ${ }^{14}$. Erbb4 in the interneurons is also involved in GABAergic synapses formation and maintenance ${ }^{7,9}$. Interestingly, the SNP (single nucleotide polymorphism) rs7598440 of ErbB4 has been shown to predict GABA levels in the cortex and cerebrospinal fluid (CSF) in healthy subjects ${ }^{15,16}$, suggesting ErbB4 could impact GABA levels in human subjects, in agreement with roles of ErbB4 in GABA circuit development and function from mouse studies.

Both NRG1 and ErbB4 are risk genes for brain disorders including major depressive disorder (MDD) and schizophrenia (SZ). A recent GWAS study of 246,363 patients with depression ${ }^{17,18}$ and MAGMA (Multimarker Analysis of GenoMic Annotation) analysis of the aggregated genetic effects identified NRG1 and ErbB4 as putative genes associated with depression. On the other hand, 
earlier family trio studies, case-controlled association and meta-analysis suggested NRG1 and ErbB4 as candidate genes for $\mathrm{SZ}^{19-25}$. Although SNPs of neither NRG1 nor ErbB4 reached genome-wide significance in a largepopulation GWAS ${ }^{26}$, perhaps as a result of allelic heterogeneity at their loci, existence of haplotypes and/or population stratification. Nevertheless, most SNPs of $N R G 1$ and ErbB4 are intronic and thus may alter gene expression. In agreement, both higher and lower levels of NRG1 and ErbB4 were reported in brain samples or peripheral blood of $\mathrm{SZ}$ patients ${ }^{27-32}$, or in neurons derived from SZ patients ${ }^{33}$. NRG1-induced phosphorylation of ErbB4 was increased in the postmortem cortex of SZ patients ${ }^{34}$. NRG1 was increased in the peripheral blood of patients with MDD although NRG1 levels were found to be normal or reduced in patients with depression, compared with healthy subjects ${ }^{35,36}$. In a rat model of depression, NRG1 was increased in the prefrontal cortex (PFC) and $\mathrm{HPF}^{37}$. In agreement, mutating NRG1 or altering its levels in mice causes hyperactive locomotion and impairs prepulse inhibition, working memory and conditional fear memory ${ }^{14,21,38-42}$. Mice with increased levels of NRG1, which mimic high levels in patients, exhibited impaired PPI, reduced social interaction, and cognitive deficits ${ }^{10,38,39,41}$. One pathological mechanism of increased NRG1 levels is thought to impair glutamate release from pyramidal neurons. However, the impact of NRG1 high-levels on the postsynaptic component remains unknown.

Here, we examined the effects of high-levels of NRG1 on dendritic spines. In cultured neurons, overexpressing NRG1 impaired spine development and maturation. In agreement, ctoNrg1 mice, which mimic high-levels of NRG1 in excitatory neurons of forebrain in schizophrenic patients, exhibited reduced spine density. Further molecular studies suggest that high-levels of NRG1 impair dendritic spines via LIMK1 activation. Our results indicate a role of NRG1 in spine homeostasis and reveal a potential mechanism of spinopathy in related disorders.

\section{Results}

Reduced spine density in neurons expressing high levels of NRG1

To investigate how the pathological condition of highlevels of NRG1 impact dendritic spines. We transfected HA-tagged, full-length NRG1 and/or GFP into cultured hippocampal neurons at 9 days in vitro (DIV) by calcium phosphate precipitation. At DIV 17-20, neurons were fixed and stained with anti-GFP antibody. The expression of NRG1 increased as we transfected in gradient (Fig. S1). Noticeably, neurons transfected with NRG1 $(1.5 \mu \mathrm{g})$ displayed reduced total spine density, compared with neurons transfected with empty vector (control) (Fig. 1a, b). The density of mature or mushroom-like (width of spine head/neck > 1.5) and immature (width of spine head/neck $<1.5$ ) spines were both reduced (Fig. 1c, d). The effects of overexpressed NRG1 on spine density were dosedependent (Fig. 1e-h). Furtherly, we used time-lapse imaging to examine the effects of high-levels of NRG1 on spine dynamics. The same secondary dendritic branch was imaged every minute for $30 \mathrm{~min}$, and percentages of stable, newborn and eliminated spines were analyzed. As shown in Fig. 1i-l, high expression of NRG1 in neurons decreased stable (Fig. 1j), but did not alter newborn and eliminated spines (Fig. 1k, l) during the imaging period. Together, these results strongly suggested high-levels of NRG1 impair spine maturation.

\section{Reduced spine density and glutamatergic transmission in ctoNrg1 mice}

To determine whether higher levels of NRG1 damage spines in vivo, we characterized ctoNrg1 mice, compound mice of CaMK2 $\alpha$-tTA and TRE-Nrg1 mice ${ }^{10}$. TRE-Nrg1 mice carry HA-tagged type I NRG1 $\beta$ cDNA under the control of the tetracycline-responsive promoter element (TRE) tetO whereas CaMK2 $\alpha$-tTA mice express tTA (tetracycline transactivator) under the control of the CaMK $2 \alpha$ promoter (Fig. S2a) ${ }^{43}$. As shown in Fig. S2b, c, different amounts of whole brain lysates (in $\mu \mathrm{g}$ of protein) from ctoNrg1 and control mice were subjected to western blotting (WB) with anti-NRG1 antibody and NRG1 levels were increased in ctoNrg1 mice. Furthermore, ctoNrg1 mice expressed higher levels of NRG1 in pyramidal neurons of the HPF, striatum (STR), PFC, and olfactory bulb (OB), but not thalamus (TH) or cerebellum (CB) (Fig. S2d, e). Overexpression of NRG1 in the HPF, STR, PFC and OB of ctoNrg1 mice was confirmed by WB with anti-HA antibody (Fig. S2d, e). The level of increase was $30-70 \%$ in forebrain regions of ctoNrg1 mice (Fig. S2d, e), consistent with a previous report ${ }^{10}$. NRG1 overexpression seemed to have little effect on overall brain structure or weight (Fig. S2f-g). Remarkably, total spine densities in the PFC (Fig. 2a, b) and hippocampal CA1 (Fig. 2e, f) were reduced. The mature (Fig. 2c, g) and immature (Fig. 2d, h) spine densities were also decreased. On the other hand, the dendritic length, branches and complexity of pyramidal neurons in PFC (Fig. S3a-d) and CA1 (Fig. S3e-h) were similar between control and ctoNrg1 mice. These results indicate that NRG1 overexpression impairs spine maturation in neurons of PFC and HPF. In support of this notion was the reduced frequency of miniature excitatory postsynaptic currents (mEPSCs) in both PFC (Fig. 2i-k) and HPF (Fig. 2l-n).

\section{Activation of LIMK1 by NRG1 overexpression}

LIMK1 is a serine/threonine kinase that has been implicated in spine development and stability ${ }^{44,45}$. It phosphorylates and thus inactivates Cofilin, an actin 


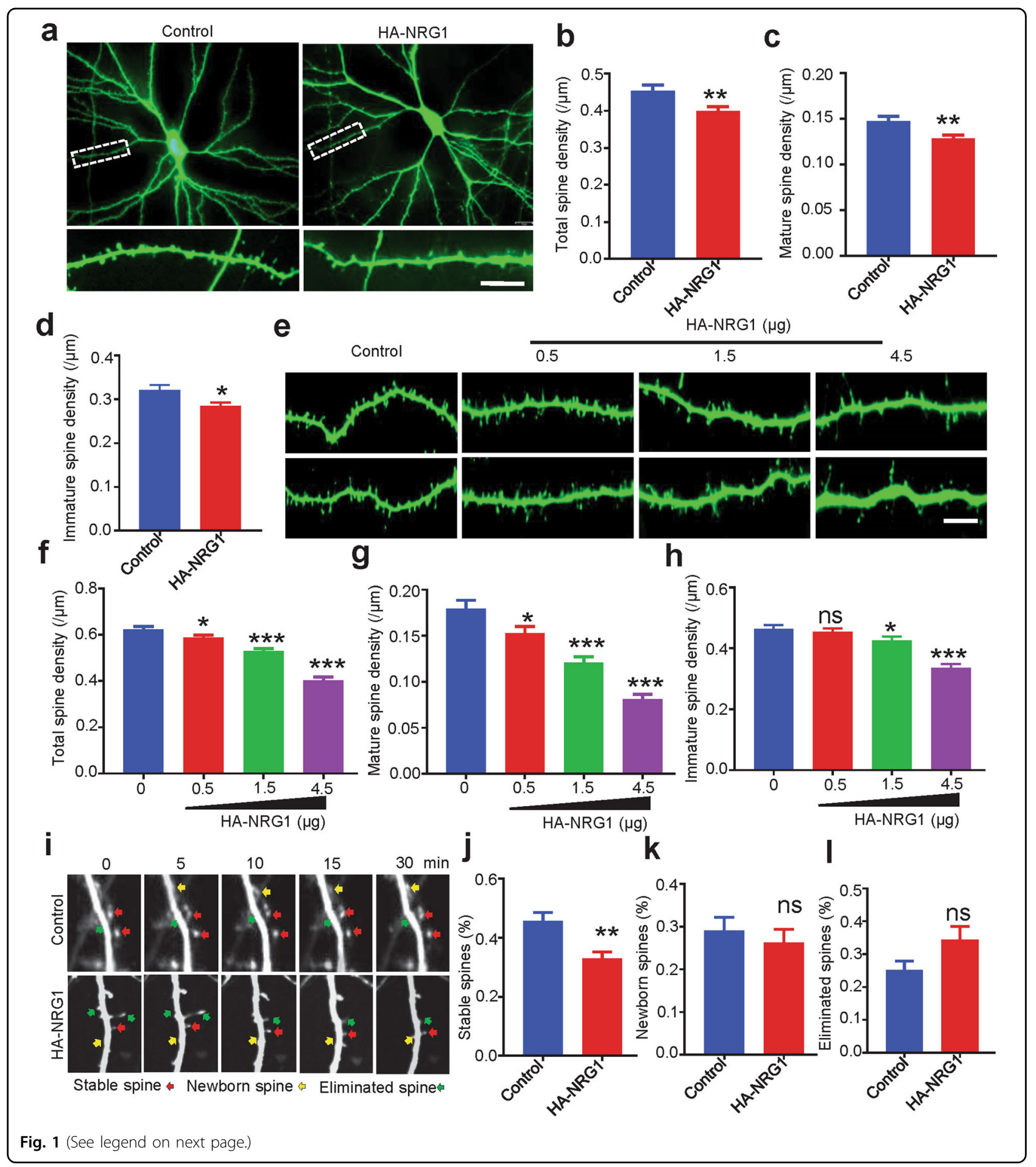

depolymerization factor that promotes the turnover and severing of actin filaments ${ }^{46,47}$. The intracellular domain (ICD) of NRG1 interacts with LIMK $1^{48}$. In light of spine deficiency in ctoNrg1 mice (Fig. 2a-h), we determined whether LIMK1 could be activated by NRG1 overexpression in vitro. HEK293 cells were transfected with
FLAG-tagged LIMK1 with or without HA-tagged NRG1 $(1.5 \mu \mathrm{g})$. As shown in Fig. 3a-c, NRG1 co-expression increased phosphorylated LIMK1 (p-LIMK1, Thr505) and Cofilin (p-Cofilin, Ser3). This effect was dose-dependent (Fig. 3d, e). These results suggest that NRG1 overexpression could activate LIMK1 and inactivate Cofilin. 
(see figure on previous page)

Fig. 1 Reduced dendritic spine density in high-expressing NRG1 neurons. a Representative images of neuronal morphology and spine density in hippocampal pyramidal neurons. Neurons were isolated at embryonic 18 (E18) rat to culture for 9 days and transfected with $1.5 \mu \mathrm{g}$ control (empty HA vector) or HA-NRG1 construct, and fixed for staining at DIV17. Scale bar, $10 \mu \mathrm{m}$. Statistical analysis of data in a for total (b), mature (c) and immature (d) spine density. $N=32$ neurons for control, $N=45$ neurons for HA-NRG1 ( $p=0.0066$ for total spine density; $p=0.0048$ for mature spine density; $p=0.0109$ for immature spine density). ${ }^{*} p<0.05$, and ${ }^{* *} p<0.01$; Student's $t$-test. e Representative images of spine density in hippocampal neurons transfected with HA-NRG1 in gradient. Scale bar, $10 \mu \mathrm{m}$. $\mathbf{f}-\mathbf{h}$ The statistical results for total (f), mature $(\mathbf{g})$ and immature (h) spine density. $N$

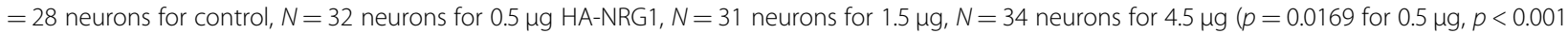
for $1.5 \mu \mathrm{g}$ and $4.5 \mu \mathrm{g}$ for total spines; $p=0.0251$ for $0.5 \mu \mathrm{g}, p<0.001$ for 1.5 and $4.5 \mu \mathrm{g}$ for mature spines; $p=0.6044$ for $0.5 \mu \mathrm{g}, p=0.0446$ for $1.5 \mu \mathrm{g}$ and $p<0.001$ for $4.5 \mu \mathrm{g}$ for immature spines). Data were shown as mean $\pm \mathrm{SEM} ;{ }^{*} p<0.05,{ }^{* *} p<0.01$, and ${ }^{* * *} p<0.001$, one-way ANOVA. i

Representative images of time-lapse imaging from hippocampal neurons transfected with HA-NRG1 or control taken at five adjacent time points during the 30-min live-imaging period. Cultured neurons were transfected with indicated constructs at DIV9 and imaged every minute for 30-min at DIV17. $N=10$ neurons for control, $N=11$ neurons for HA-NRG1. j-I Quantitative analysis for percentages of stable (red arrow), newborn (yellow arrow) and eliminated (green arrow) spines. $p=0.003$ for stable spines, $p=0.571$ for newborn spines, and $p=0.07$ for eliminated spines. Data were shown as mean $\pm \mathrm{SEM} ;{ }^{* *} p<0.01 ; \mathrm{ns}, p>0.05$; Student's $t$-test.

To confirm this effect in vivo, p-LIMK1 and p-Cofilin were detected in ctoNrg1 mice. NRG1 protein was detectable in both homogenates (Hom, whole-cell lysates) and postsynaptic density (PSD) fraction of both control and ctoNrg1 mice. Its level was higher in ctoNrg1 mice than that of control mice (Fig. 3f, g). Remarkably, pLIMK1 was increased in PSDs of ctoNrg1 mice, compared with control mice, suggesting that NRG1 overexpression may lead to higher LIMK1 activity (Fig. 3h, i). Likewise, pCofilin was increased in ctoNrg1 PSDs, compared with controls (Fig. $3 \mathrm{~h}, \mathrm{j}$ ). Together, these results suggest that NRG1 overexpression activated LIMK1 and thus inactivated $\mathrm{p}$-cofilin in the PSDs in vivo.

Inactivation of LIMK1 by blocking NRG1-LIMK1 interaction

The hypothesis that NRG1 interacting with LIMK1 increases its activity predicts that LIMK1 is less active when the NRG1-LIMK1 interaction is blocked. To test this, HEK293 cells were co-transfected with FLAG-tagged LIMK1 and HA-tagged NRG1 derivative constructs (HAFL, HA- $\triangle 266-422$ ) (Fig. 4a). As shown in Fig. 4b, HA-FL, but not HA- $\triangle 266-422$, was detectable in the complex precipitated with anti-FLAG antibody, indicating NRG1ICD interacts with LIMK1 in a manner dependent on the 266-422 fragment, in agreement with a previous report ${ }^{48}$. In addition, we showed that the Myc-tagged NRG1-ICD (Myc-ICD) and 266-422 fragment (Myc-266-422) could be precipitated with anti-FLAG antibody, indicating that this domain was sufficient to interact with LIMK1 (Fig. 4c, d). Having identified the domain required and sufficient to interact with LIMK1, we determined whether this domain was able to inhibit the interaction between NRG1 and LIMK1. HEK293 cells were transfected with increasing concentrations of Myc-266-422 together with Myc-ICD and FLAG-LIMK1. As shown in Fig. 4e, f, the amount of Myc-ICD was reduced in the precipitated LIMK1 complex as Myc-266-422 concentrations increased. These results suggest that the 266-422 fragment can inhibit NRG1-LIMK1 interaction. Notice that the 266-422 fragment alone was unable to alter LIMK1 phosphorylation (Fig. $4 \mathrm{~g}, \mathrm{~h}$ ), suggesting that this fragment blocks the NRG1-LIMK1 interaction without altering LIMK1 phosphorylation by itself. In addition, NRG1 mutant without the 266-422 (HA- $\triangle 266-422$ ) was unable to activate LIMK1, suggesting that the interaction of NRG1 and LIMK1 was crucial (Fig. 4i, j). Together, these results suggest the LIMK1 activation requires the interaction with NRG1-ICD.

\section{Reduced spine deficiency by LIMK1 inactivation and by blocking the NRG1-LIMK1 interaction}

Our results suggested that high-levels of NRG1 activate LIMK1 activity which was associated with spine density reduction (Fig. 5a). To demonstrate a causal relationship, we determined whether NRG1 overexpression-mediated spine deficits could be attenuated by reducing LIMK1 activity. First, neurons were treated with damnacanthal (Dmn), an anthraquinone derivative that inhibits LIMK1 and Lck, but not CaMK2a, ROK, PKC $\alpha$, or PAK3 ${ }^{49}$. As shown in Fig. 5b-d, Dmn inhibited LIMK1 and Cofilin phosphorylation in a dose-dependent manner. Treatment with $10 \mu \mathrm{M}$ Dmn, a concentration that effectively inhibits LIMK1, but not Lck $^{49}$, increased the spine densities in hippocampal neurons overexpressing HA-NRG1, compared with neurons treated with vehicle (DMSO) (Fig. 5e-h). These results support the hypothesis that NRG1 overexpression causes spine deficiency by activating LIMK1. Next, we studied the effect of the 266-422 fragment, which could block the NRG1-LIMK1 interaction and thus reduce LIMK1 activity (Fig. 4e-j). Hippocampal neurons transfected with HA-NRG1 exhibited reduced spine densities, compared with control neurons. This inhibitory effect was blocked by co-expressing the 266-422 fragment (Fig. 5i-l). The spine density decreased and with no effect for dendritic length in neurons overexpressing this fragment alone (Fig. S4a-d). A parsimonious explanation of these results is that NRG1 overexpression causes spine deficits by activating LIMK1 and inactivating Cofilin. 


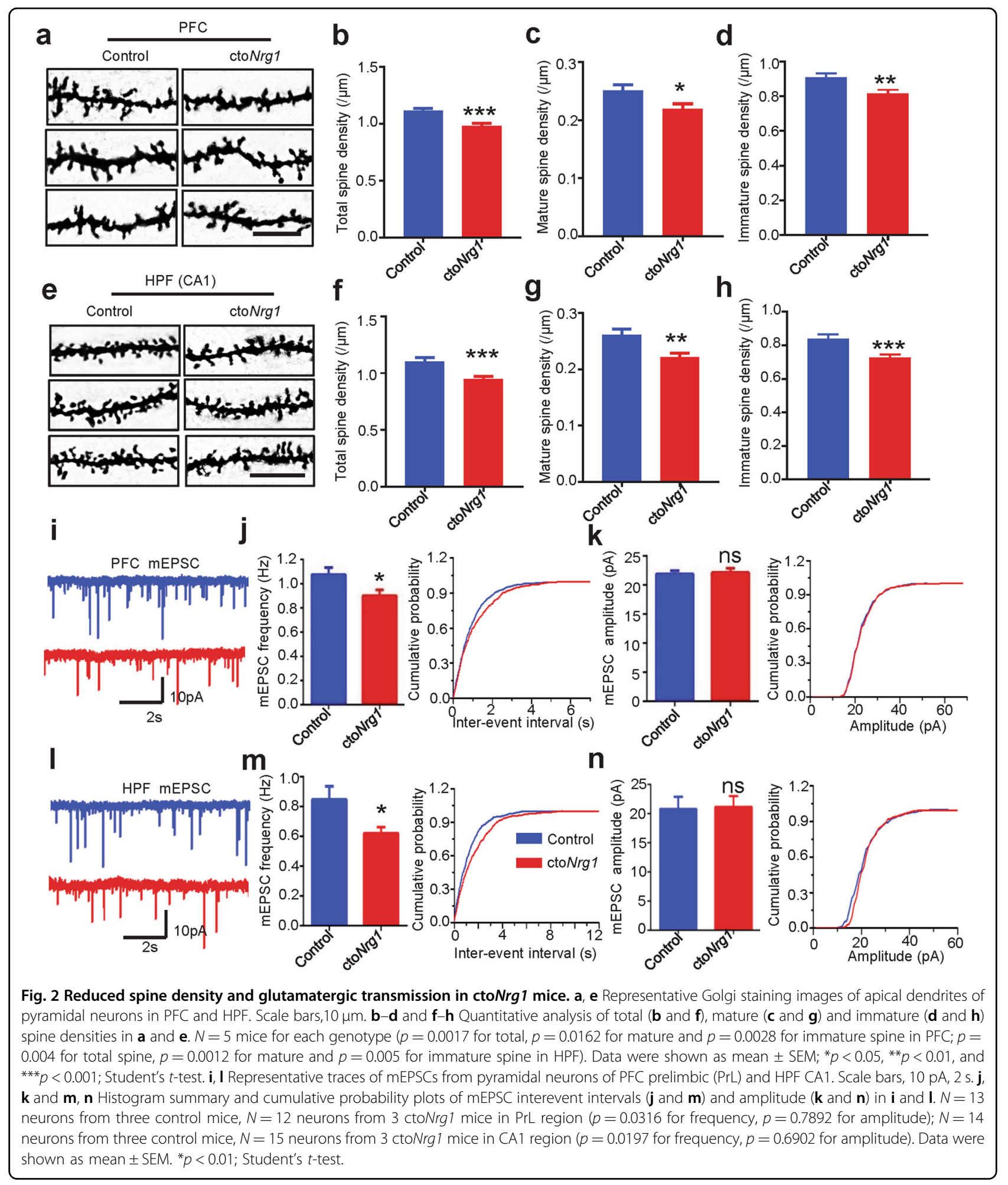

Recovery of spine density in Dox-treated ctoNrg1 mice

To determine whether NRG1 overexpression-induced spine deficiency is reversible, ctoNrg1 mice were treated with Dox $(1 \mathrm{mg} / \mathrm{kg}$ in drinking water) at the age of
6 weeks for 4 weeks (Fig. 6a). Compared with ctoNrg1 mice with regular water, NRG1 level was recovered to normal level in the forebrain of Dox-treated ctoNrg1 mice (Fig. 6b, c). NRG1 levels were similar between TRE-Nrg1 


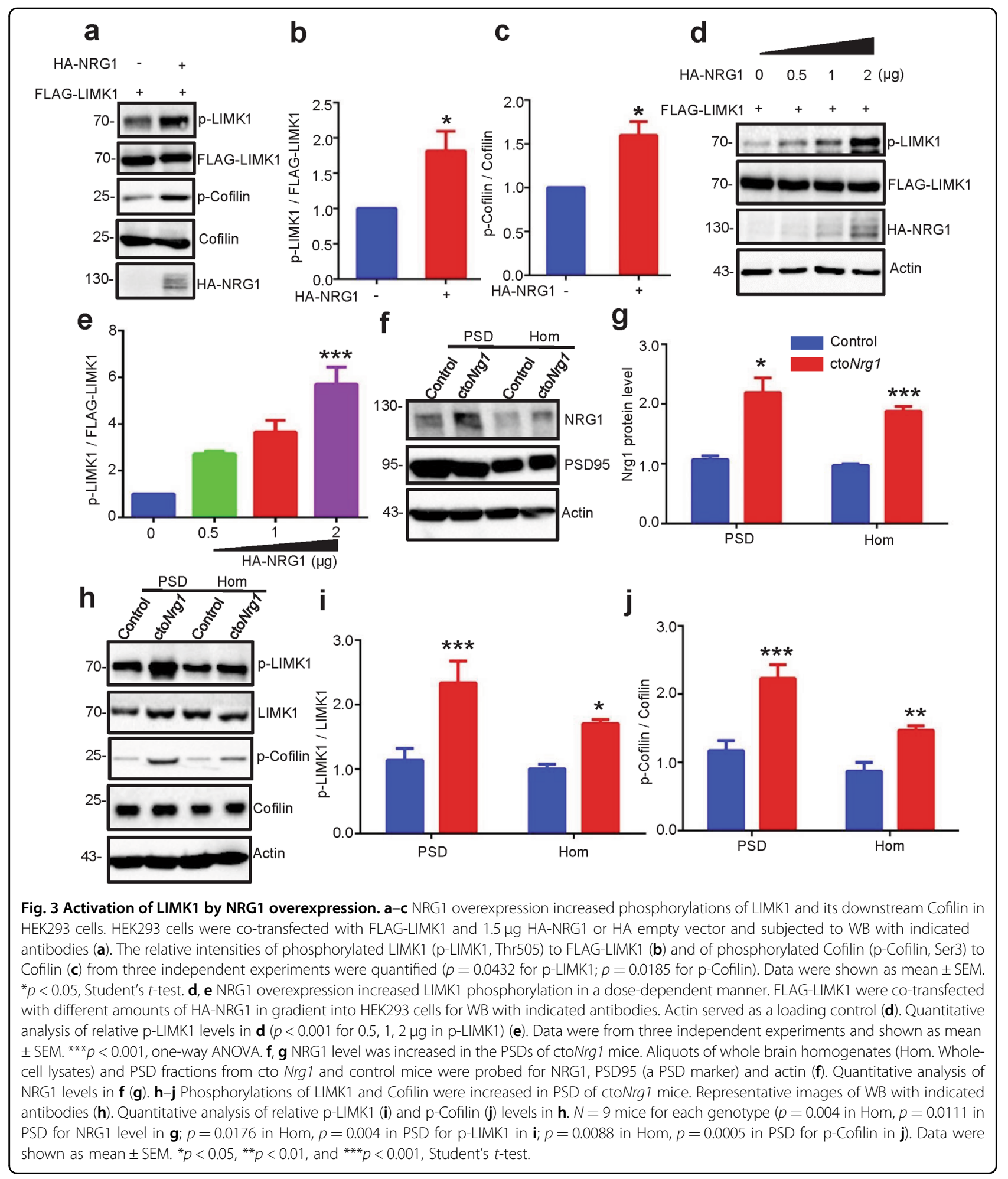

(control) and Dox-treated ctoNrg1 mice, suggesting that NRG1 was reduced to a normal level after Dox treatment. Noticeably, the spine density and maturation in Doxtreated ctoNrg1 mice were increased, compared with those in untreated ctoNrg1 mice, in both PFC (Fig. 6d-g) and HPF (Fig. 6h-k), indicating that spine deficiency by NRG1 overexpression could be rescued by reducing NRG1 levels. The spine densities of Dox-treated ctoNrg1 mice remained lower than those in control mice in the HPF, suggesting that the rescue effect was partial. 


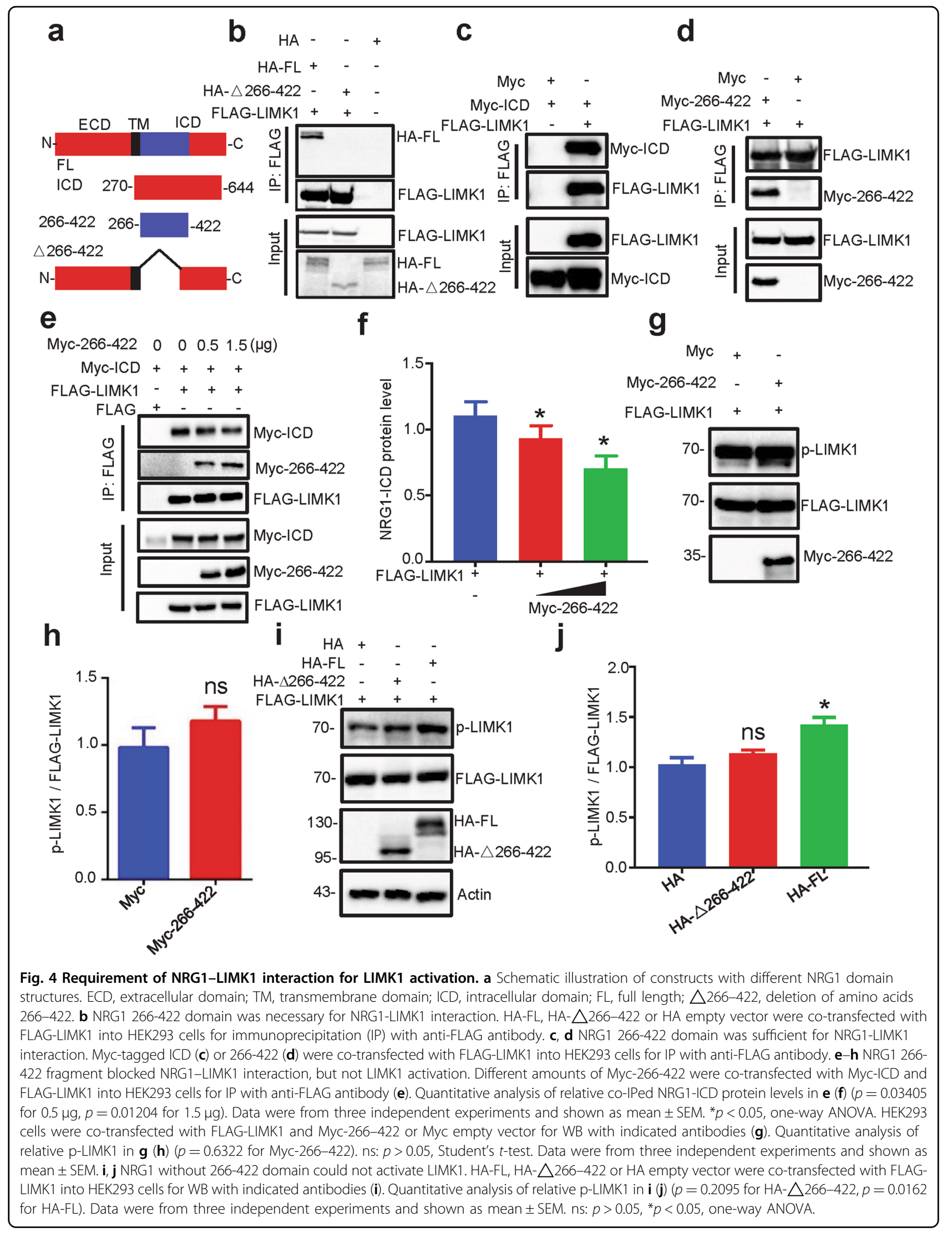




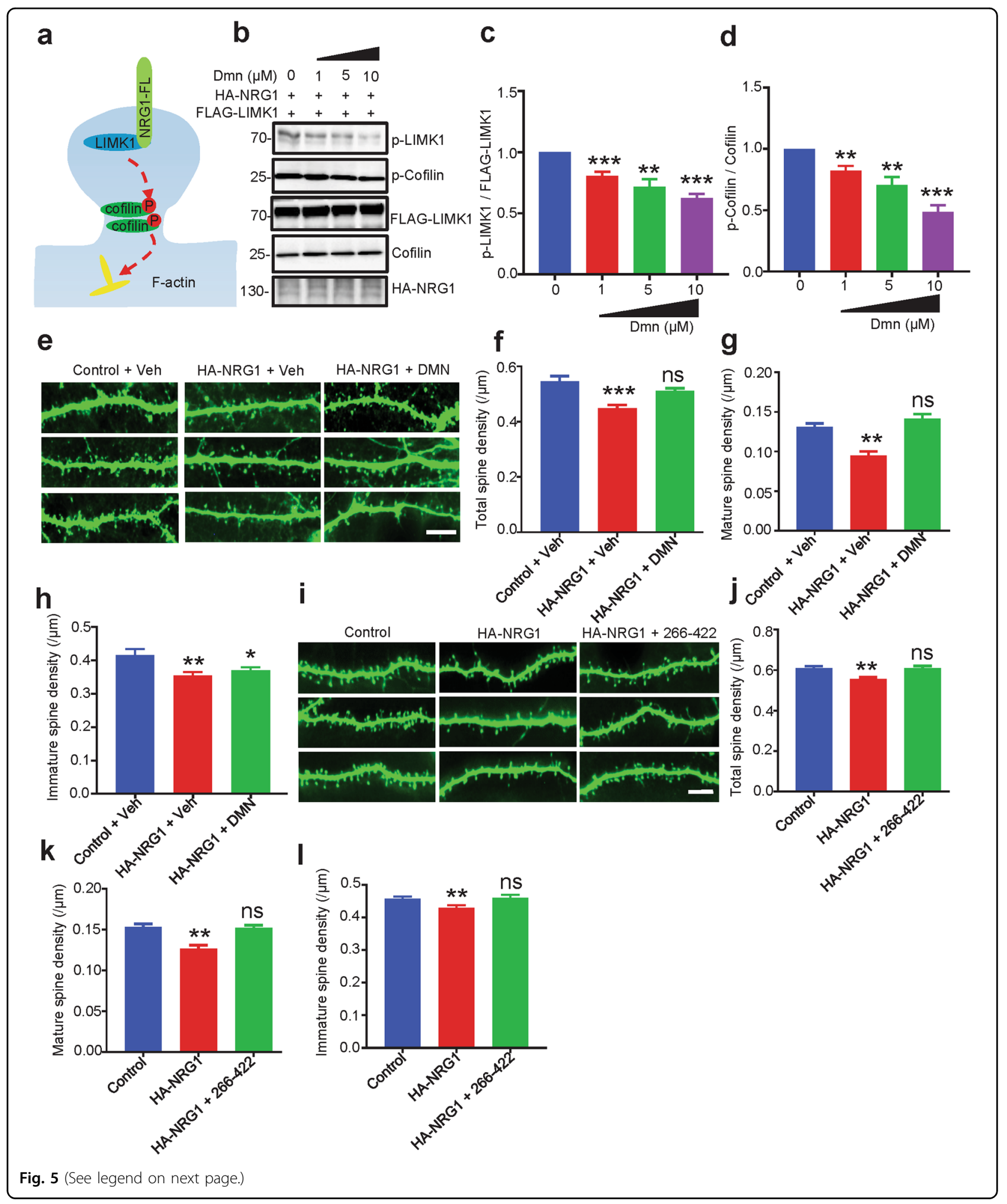

However, in the PFC, there was no difference in spine densities between control and Dox-treated ctoNrg1 mice, suggesting a complete rescue. In addition, the LIMK1 and its downstream Cofilin phosphorylation were also restored to the normal level compared with control in the PSD area of ctoNrg1 mice treated with Dox (Fig. 6l, m). 
(see figure on previous page)

Fig. 5 Reduced spine deficiency by LIMK1 inhibition and by blocking NRG1-LIMK1 interaction. a A working model shows NRG1 interacted with and activated LIMK1 to affect dendritic spine development in the PSD. b-d NRG1-induced LIMK1 activation was inhibited by LIMK1 inhibitor Dmn. HEK293 cells co-transfected with HA-NRG1 and FLAG-LIMK1 were treated with different concentrations of Dmn for $4 \mathrm{~h}$ and subjectd to WB with indicate antibodies (b). Quantitative analysis of relative p-LIMK1 (c) and p-Cofilin (d) levels in $\mathbf{b}(p=0.0009$ for $1 \mu \mathrm{M}, p=0.004$ for $5 \mu \mathrm{M}, p<0.001$ for $10 \mu \mathrm{M}$ in $p$-LIMK1; $p=0.0038$ for $1 \mu \mathrm{M}, p=0.0036$ for $5 \mu \mathrm{M}, p<0.001$ for $10 \mu \mathrm{M}$ in $p$-Cofilin). Data were shown as mean \pm SEM. ${ }^{*} p<0.05,{ }^{* *} p<0.01$, ${ }^{* * *} p<0.001$, one-way ANOVA. e-h Spine deficiency in NRG1 high-expressing neurons was rescued by Dmn treatment. Representative images of dendritic spines of cultured neurons. Scale bar, $10 \mu \mathrm{m}(\mathbf{e})$. Primary hippocampal neurons were transfected with HA-NRG1 or control at DIV9 and treated with $10 \mu \mathrm{M}$ Dmn or its vehicle DMSO for $12 \mathrm{~h}$. Quantitative analysis of total $(\mathbf{f})$, mature $(\mathbf{g})$, and immature $(\mathbf{h})$ spine densities in e. $N=21$ neurons for control + Veh; $N=24$ neurons for HA-NRG1 + Veh; $N=27$ neurons for HA-NRG1 + Dmn $(p<0.001$ for HA-NRG1 + Veh, $p=0.0581$ for HA-NRG1 + Dmn in total spine; $p<0.001$ for HA-NRG1 + Veh, $p=0.2183$ for HA-NRG1 + Dmn in mature spine; $p=0.0037$ for HA-NRG1 + Veh in immature spine, $p=0.0117$ for HA-NRG1 + Dmn in immature spine). Data were shown as mean \pm SEM. ${ }^{* *} p<0.01,{ }^{* * *} p<0.001$, one-way ANOVA. i-I Spine deficiency in NRG1 high-expressing neurons was rescued by NRG1 266-422 fragment. Representative images of dendritic spines of cultured neurons (i). Scale bar, $10 \mu \mathrm{m}$. Hippocampal neurons (DIV9) were transfected with HA-NRG1 or HA-NRG1 plus 266-422, and fixed at DIV17 for immunostaining. Quantitative analysis of total $\mathbf{( j )}$, mature $(\mathbf{k})$ and immature (I) spine densities in $\mathbf{i} . N=27$ neurons for control, $N=35$ for HA-NRG1, $N$ $=29$ neurons for HA-NRG1 + 266-422 ( $p=0.006$ for HA-NRG1, $p=0.9457$ for HA-NRG1 + 266-422 in total spine; $p=0.0015$ for HA-NRG1, $p=0.8421$ for HA-NRG1 + 266-422 in mature spine; $p=0.007$ for HA-NRG1, $p=0.8374$ for HA-NRG1 + 266-22 in immature spine). Data were shown as mean \pm SEM. ns, $p>0.05,{ }^{* *} p<0.01$, and ${ }^{* * *} p<0.001$, one-way ANOVA.

Together, these results suggest that high-levels NRG1mediated spine deficiency could be attenuated by reducing NRG1 levels in young adult mice and suggest that NRG1 is critical in regulating spine density.

\section{Discussion}

Our findings provided a new pathophysiological mechanism of NRG1 for SZ. First, spine density and its maturation were reduced in cultured neurons highexpressing NRG1 (Fig. 1). The spine deficits were also observed in the PFC and HPF of ctoNrg1 mice overexpressing NRG1 in forebrain excitatory neurons (Fig. 2). Second, high-levels of NRG1 activated LIMK1 and inactivated Cofilin in vitro and in vivo (Fig. 3). Third, either inhibiting LIMK1 activity or blocking NRG1-LIMK1 interaction attenuated NRG1 overexpression-induced spine deficits (Fig. 5). These observations demonstrate that spine development requires proper levels of NRG1 and high-levels of NRG1 impair spine formation and maturation. These results may contribute to our understanding of mechanisms of NRG1 participating in relevant brain disorders.

The cytoskeleton of the dendritic spine is formed by filamentous actin (F-actin), which supports the spine shape and drives the postsynaptic signaling pathway to maintain spine stability and dynamic ${ }^{50,51}$. The small GTPases of Rho family, mostly including RhoA, Rac1, and Cdc42, promote or suppress the actin polymerization by active GTP-bound and inactive GDP-bound change states to regulate spine morphogenesis ${ }^{52-54}$. Downstreams of Rho GTPases include LIMK1, Wiskott-Aldrich syndrome proteins (WASPs), ARP and WASP-family verprolin homologous (WAVEs) ${ }^{45,55,56}$. Rac1 activates the downstream effectors p21-activated kinase (PAK), LIMK1, and F-actin-binding protein Cofilin to regulate actin polymerization and stabilize dendritic spines ${ }^{57,58}$. Spine morphology and development are impaired by LIMK1 deficiency or miR-134-mediated inhibition of LIMK1 translation $^{45,59}$. LIMK1 is a serine/threonine kinase that regulates actin dynamics by phosphorylating its downstream Cofilin ${ }^{46,47}$. NRG1 via its ICD interacts with LIMK $1^{60}$, and high-levels NRG1 recruit LIMK1 into synaptic areas for overactivation to impair synaptic transmission in ctoNrg1 mice ${ }^{10}$. Phosphorylated LIMK1 and Cofilin were also increased in the PSDs of ctoNrg1 mice (Fig. $3 \mathrm{~h}-\mathrm{j}$ ). We showed that NRG1 overexpression induced spine deficits could be partially restored by inhibiting LIMK1 activation (Fig. 5e-h) or NRG1-LIMK1 interaction (Fig. $5 \mathrm{i}-\mathrm{l}$ ). It is very difficult to discriminate if presynaptic LIMK1/Cofilin signaling was involved in dendritic spine maturation in vivo. Even though some have reported that presynaptic signaling is crucial for synaptogenesis, dendritic spine formation and maintenance are normal in the absence of presynaptic neurotransmitter secretion ${ }^{61}$. Reducing NRG1 protein levels in ctoNrg1 mice reduced LIMK1and Cofilin phosphorylations and attenuated spine deficits (Fig. 6). However, the rescue experiments by crossing ctoNrg1 with LIMK1 knockout mice could be performed to validate this mechanism in vivo.

In postmortem schizophrenic patients, spine density is decreased from $23 \%$ to $66 \%$ compared with normal control in PFC layer 3 pyramidal neurons ${ }^{62-64}$, but not for layers 5 and $6^{65}$. The spine volume is decreased by $35 \%$, and the total spine number is decreased by $47 \%$ in the schizophrenic hippocampal CA3 region ${ }^{66}$. Spine deficit might be a significant hallmark for SZ. Here we also observed spine development deficits in ctoNrg1 mice, which display SZ-related abnormal behaviors. Interestingly, it has been reported that overexpressing type-III NRG1 under the Thy1.2 promoter in mice causes abnormal spine morphology, but normal spine density ${ }^{67}$. 


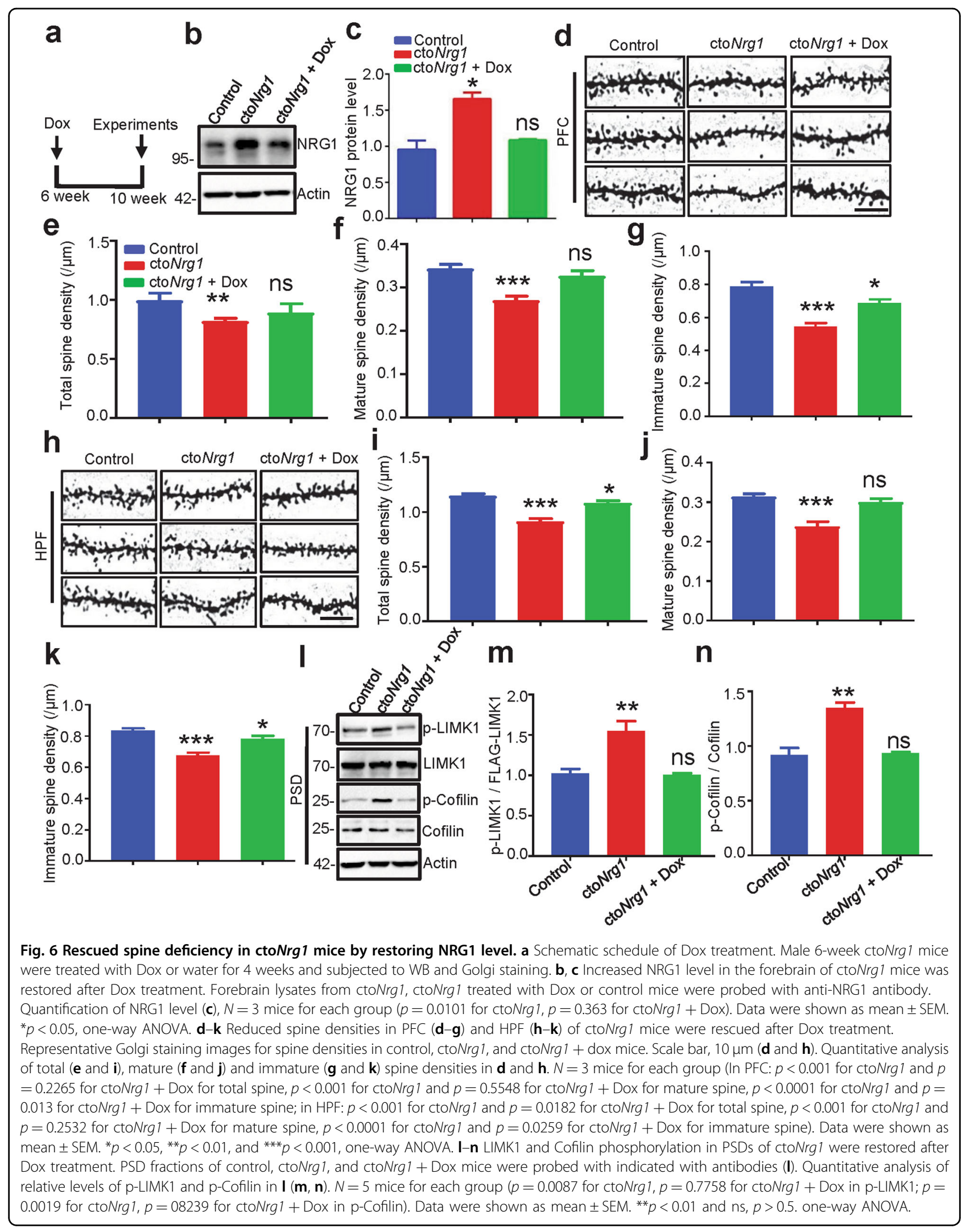


Due to the unstable expression pattern of Thy1.2 promoter $^{68}$, it might not be an ideal model to mimic high expression levels and regions of NRG1 in schizophrenic patients. However, in our ctoNrg1 mice, NRG1 was overexpressed under CamK $2 \alpha$ promoter and in a tTAinduced manner (Fig. S2a). It has been shown that ctoNrg1 mice increase NRG1 level by $50-100 \%$ in the forebrain, similar to that in schizophrenic forebrains. So, the ctoNrg1 mice are a relatively better model for mimicking high-levels of NRG1 under SZ pathological conditions.

Previous studies suggested that elevated NRG1 levels or signaling are associated with SZ. The NRG1 mRNA and protein levels are increased in the PFC and HPF of schizophrenic patients ${ }^{27,28,69,70}$. Mimicking high levels of NRG1 in mice also results in relevant behavioral deficits $^{10,38,39,41}$. Continuous high expressing NRG1 leads to impaired glutamatergic and GABAergic transmission ${ }^{10}$. Recently, it has been reported that NRG1 and ErbB4 are both risk genes for $\mathrm{MDD}^{17,18}$. Although NRG1 mRNA level is increased in the peripheral blood of patients with MDD, its level in the brain is still unclear ${ }^{35,36}$. And dysregulation of the NRG1 level has been observed in different rodent depression models. NRG1 protein level is increased in the PFC and HPF in a rat model of chronic unpredictable mild stress $(\mathrm{CUMS})^{37}$. However, in the mouse model of chronic social defeat stress (CSDS), NRG1 protein level was decreased in medial PFC (mPFC) and $\mathrm{HPF}^{71,72}$. Moreover, overexpressing NRG1 in mPFC through virus attenuates depressive-like behaviors in CSDS mice, suggesting NRG1 deficiency in mice mPFC played a key role for stress susceptibility ${ }^{72}$. Therefore, NRG1 plays a critical role in depression based on its protein levels. Interestingly, the phosphorylation levels of LIMK1 and Cofilin, but not protein levels, are increased in the mPFC of the CUMS, CSDS and chronic restraint stress (CRS) mouse models ${ }^{73}$. Considering spine synapses density is decreased in the dorsolateral PFC (dIPFC) layer 2/3 of MDD patients ${ }^{74}$, high-levels NRG1 induced LIMK1 activation might also contribute to the spine deficits in MDD. In the future, ctoNrg1 mice could be exposed to stress and subjected to depressive-like behavioral tests to detect if high-levels NRG1 induce stress susceptibility. Taken together, NRG1 plays a critical role in the central nervous system based on its gene-dosage balance, and abnormal levels or activity of NRG1 could potentially contribute to the pathogenesis of relevant neurological disorders.

\section{Materials and methods \\ Animals}

CtoNrg1 mice were described as previously ${ }^{10}$. All mice were housed in a constant temperature and humidity chamber at $23^{\circ} \mathrm{C}$, and sufficient food and water were administered daily. No more than five adult mice per cage were subjected to a 12-h light/dark cycle under standard conditions. All the mice were guaranteed to be hygienic. The animal experiments were carried out following the "Guidelines for the Care and Use of Laboratory Animals" promulgated by Nanchang University.

\section{Cell culture and transfection}

Human embryonic kidney (HEK) 293 cells were cultured in Dulbecco's modified Eagle's medium (DMEM) (Gibco) supplemented with 10\% fetal bovine serum (FBS) (Gibco). Transient transfection was performed using polyethylenimine (PEI) (Sigma, 408727), as described before $^{75}$. Briefly, cells were cultured in $100 \mathrm{~mm}$ dishes and at $\sim 70 \%$ confluence were incubated with precipitates formed by $5 \mu$ g of plasmid DNA and $280 \mu \mathrm{L}$ of $0.05 \%$ PEI (wt/vol). Cells were harvested $24-48 \mathrm{~h}$ post-transfection.

Cultures of primary hippocampal neurons were prepared from embryonic day (E) 18 Sprague-Dawley rats as described previously ${ }^{8}$. Briefly, hippocampi were isolated and kept separate from one another in HBSS on ice. Following digestion in $0.25 \%$ trypsin plus $0.1 \mathrm{mg} / \mathrm{mL}$ DNase I (one HPF in $1 \mathrm{~mL}$ ) at $37^{\circ} \mathrm{C}$ for $20 \mathrm{~min}$. Dissociated cells were resuspended in plating media (DMEM supplemented with $10 \% \mathrm{FBS}$ ) and plated at a density of $1 \times 10^{5}$ or $2 \times 10^{5}$ per well onto poly-D-lysine-coated 20 $\mathrm{mm}$ coverslips (WHB) in 12-well plates (Corning). Cells were incubated for $4 \mathrm{~h}$ before replacing with maintenance medium [neurobasal medium (Gibco) supplemented with 2\% B-27 supplement (Gibco), 1\% GlutaMax (Gibco), and $1 \%$ penicillin/streptomycin (Gibco)]. Neurons were maintained at $37^{\circ} \mathrm{C}$ in $5 \% \mathrm{CO}_{2}$, with half of the medium changed every $2-3$ days.

For transfection in neurons, calcium phosphate precipitation was performed as described previously ${ }^{75}$. Briefly, the neurons were serum-starved with pre-heated DMEM for $2 \mathrm{~h}$ at $37^{\circ} \mathrm{C}$ in $10 \% \mathrm{CO}_{2}$. For each well of 12 well plate, $1-6 \mu \mathrm{g}$ DNA in 1-6 $\mu \mathrm{L}$ was mixed with $5 \mu \mathrm{L}$ $2.5 \mathrm{M} \mathrm{CaCl}_{2}$ in $\mathrm{ddH}_{2} \mathrm{O}$ (total volume $50 \mu \mathrm{L}$ ), and further mixed with $50 \mu \mathrm{L}$ of Hepes-buffered saline containing (in millimoles): $274 \mathrm{NaCl}, 10 \mathrm{KCl}, 1.4 \mathrm{Na}_{2} \mathrm{HPO}_{4}, 15$ glucose, and 42 Hepes, $\mathrm{pH}$ 7.05. Resulting DNA-calcium phosphate precipitates were added into neurons. Morphology was studied 3-7 days later.

\section{Western blotting}

For protein expression detection, tissues were homogenized in PBS plus protease and phosphatase inhibitors. Then the homogenates were lysed in equal volume of $2 \times$ RIPA buffer [0.2\% SDS (wt/vol), 1\% sodium deoxycholate (wt/vol) and 2\% Nonidet P-40 (vol/vol) in PBS] plus protease and phosphatase inhibitors. Lysates were centrifuged at $12,000 \times g$ for $20 \mathrm{~min}$ at $4{ }^{\circ} \mathrm{C}$ to remove debris. The supernatants were subjected to Bradford assay 
(Pierce) to measure protein concentration and diluted in SDS sample buffer.

Protein samples $(10-20 \mu \mathrm{g})$ were resolved by SDS-PAGE and transferred to PVDF membrane (Millipore). The membrane was immunoblotted with primary and secondary antibodies, and immunoreactive bands were visualized by enhanced chemiluminescence under gel documentation system (Bio-Rad). Densitometric quantification of protein band intensity was performed by using ImageJ. Antibodies were diluted with primary antibody dilution buffer (TBS $+1 \%$ TritonX-100 $+5 \%$ BSA) for WB: anti-HA (Biolengend, mouse,1:500, 901513), anti-FLAG (Sigma, mouse, 1:2000, 1804), antiMyc (SCTB, mouse, 1:1000, sc-40), anti-Cofilin (SCTB, rabbit, 1:500, sc-33779), anti-p-Cofilin (SCTB, rabbit, 1:500, sc-21867R), anti-LIMK1 (mouse, BD, 1:1000, 611748), anti- $p$-LIMK1 (rabbit, cell signaling, 1:1000, 3841), anti-PSD95 (mouse, millipore, 1:1000, MABN1194), anti-Neuregulin-1 (rabbit, SCTB, 1:500, sc393006), anti- $\beta$-actin (rabbit, SCTB, 1:2000,sc-130656) and anti-GFP (mouse, SCTB, sc-9996).

\section{Immunoprecipitation}

Immunoprecipitation was performed as described previously $^{76}$. For co-immunoprecipitation (co-IP), transfected HEK293 cells were lysed in IP buffer containing (in millimoles): 20 Tris, pH7.6, $50 \mathrm{NaCl}, 1$ EDTA, $1 \mathrm{NaF}$, $0.5 \%$ Nonidet P-40 ( $\mathrm{vol} / \mathrm{vol})$, with protease and phosphatase inhibitors. Samples were centrifuged at 12,000 $\times g$ for $20 \mathrm{~min}$ at $4{ }^{\circ} \mathrm{C}$ to remove debris. Lysates $(1-2 \mathrm{mg})$ were incubated with corresponding antibody $(1-2 \mu \mathrm{g})$ at $4{ }^{\circ} \mathrm{C}$ for either 3-4h or overnight and then incubated with 10-15 $\mu \mathrm{L}$ Protein A/G magnetic agarose beads (Pierce) at $4{ }^{\circ} \mathrm{C}$ for $1 \mathrm{~h}$. Samples were washed with IP buffer and resuspended in SDS sample buffer. Then the samples were subjected to WB.

\section{Time-lapse imaging and analysis of dendritic spines}

Live imaging of cultured neurons was performed as described previously with modifications ${ }^{77}$. Cultured rat hippocampal neurons were transfected by Calcium phosphate precipitation at DIV9 and subjected to live imaging at DIV15. Z-stack images of secondary dendrites from transfected neurons were imaged every minute for 30 min, using an Olympus FV1000 confocal microscope with a $\times 40$ (NA 1.35) objective for time-lapse imaging. Images were collapsed into $2 \mathrm{D}$ projections and analyzed with ImageJ software. Stable spines were defined as protrusions with stable morphology during the entire imaging session; newborn spines were those emerging protrusions after imaging, regardless of the time they emerged and whether they persisted during the entire imaging session; eliminated spines were present at the beginning of imaging, but disappeared during the imaging session.

\section{Immunostaining}

Immunostaining was performed as described previously with modifcations ${ }^{75}$. Primary cultured neurons were fixed with $4 \%$ paraformaldehyde (PFA)/4\% sucrose (wt/vol) for $15 \mathrm{~min}$. After washing three times with PBS, neurons were incubated with primary antibody diluted in GDB buffer (30 mM phosphate buffer, $\mathrm{pH} 7.4$, containing $0.2 \%$ gelatin, $0.6 \%$ Triton $\mathrm{X}-100$, and $0.9 \mathrm{M} \mathrm{NaCl})$ at $4{ }^{\circ} \mathrm{C}$ overnight. After washing three times with washing buffer $(20 \mathrm{mM}$ phosphate buffer and $0.5 \mathrm{M} \mathrm{NaCl}$ ), neurons were incubated with the corresponding Alexa Fluor-conjugated secondary antibodies (diluted in GDB buffer) at room temperature for $1 \mathrm{~h}$. The images were obtained by Olympus, FSX100.

\section{Subcellular fractionation}

Mice brain subcellular fractions were performed as described previously with modifications ${ }^{76}$. Adult mice cerebral cortices were homogenized in 10 volumes of HEPES-buffered sucrose (0.32 $\mathrm{M}$ sucrose, $4 \mathrm{mM}$ HEPES/ $\mathrm{NaOH}, \mathrm{pH}$ 7.4) with a glass-Teflon homogenizer. The homogenate (Hom) was centrifuged at $1000 \times g$ for $10 \mathrm{~min}$ to remove the nuclear fraction and unbroken cells. The supernatant (S1) was then centrifuged at 10,000 $\times g$ for $15 \mathrm{~min}$ to yield the crude synaptosomal fraction and the supernatant (S2). This pellet was resuspended in 10 vol of HEPES-buffered sucrose and then centrifuged at $10,000 \times g$ for another $15 \mathrm{~min}$. The resulting pellet (P2) was lysed by hypo-osmotic shock in water, rapidly adjusted to $4 \mathrm{mM}$ HEPES, and mixed constantly for $30 \mathrm{~min}$ (on ice). The lysate was then centrifuged at $25,000 \times g$ for 20 min to yield the supernatant (S3, crude synaptic vesicle fraction) and a pellet (P3, lysed synaptosomal membrane fraction). The pellet was resuspended in HEPES-buffered sucrose, carefully layered on top of a discontinuous gradient containing 0.8-1.0-1.2 M sucrose (top to bottom), and centrifuged at $150,000 \times g$ for $2 \mathrm{~h}$. The gradient yields a floating myelin fraction (G1), a light membrane fraction at the $0.8 \mathrm{M} / 1.0 \mathrm{M}$ sucrose interface (G2), a synaptosomal plasma membrane (SPM) fraction at the $1.0 \mathrm{M} / 1.2 \mathrm{M}$ sucrose interface (G3), and a mitochondrial fraction as the pellet (G4). Collect the G3 layer and add equal volume HEPES-buffered sucrose then centrifuged at 20,000 $\times g$ for $15 \mathrm{~min}$ to get the SPM. Resuspending the SPM with $1 \%$ Triton X-100 in $50 \mathrm{mM}$ $\mathrm{HEPES} / \mathrm{NaOH}(\mathrm{pH}$ 8) on ice for $15 \mathrm{~min}$ and then centrifuged at $20,000 \times g$ for $15 \mathrm{~min}$ to yield the soluble presynaptic membrane protein and the pellet is the PSD (Soluble in $2 \%$ SDS PBS buffer at RT).

\section{Electrophysiological recordings}

Electrophysiological recordings were performed as described previously ${ }^{10}$. Briefly, slices were placed in recording chamber that was perfused $(3 \mathrm{~mL} / \mathrm{min})$ with 
ACSF containing $(126 \mathrm{mM} \mathrm{NaCl}, 3 \mathrm{mM} \mathrm{KCl}, 1.25 \mathrm{mM}$ $\mathrm{NaH}_{2} \mathrm{PO}_{4}, \quad 1.0 \mathrm{mM} \quad \mathrm{MgSO}_{4}, \quad 2.0 \mathrm{mM} \quad \mathrm{CaCl}_{2}, 26 \mathrm{mM}$ $\mathrm{NaHCO}_{3}$, and $10 \mathrm{mM}$ Glucose) at $32-34{ }^{\circ} \mathrm{C}$. Whole-cell recording from the PFC and HPF pyramidal neurons was aided with infrared optics using an upright microscope equipped with a $40 \times$ water-immersion lens (Olympus, BX51WI) and infrared-sensitive CCD camera. The pipette (input resistance: 2-4 M 2 ) solution contained $135 \mathrm{mM}$ Cs-methanesulfonate, $8 \mathrm{mM} \mathrm{NaCl}, 10 \mathrm{mM}$ HEPES, $10 \mathrm{mM}$ phosphocreatine, $4 \mathrm{mM}$ ATP-Mg, $0.3 \mathrm{mM}$ GTP$\mathrm{Na}, 0.3 \mathrm{mM}$ EGTA, and $5 \mathrm{mM}$ QX314 (Tocris Bioscience, \#0190) (pH, 7.3, $295 \mathrm{mOsm}$ ). To measure miniature EPSCs (mEPSCs) were blocked with $20 \mu \mathrm{M}$ bicuculline methiodide (BMI) (Tocris Bioscience, \#0130).

\section{Golgi staining}

Golgi staining was prepared as described previously ${ }^{78}$. The Golgi staining regent (FD Rapid GolgiStainTM Kit, cat: PK401). Briefly, the animal brain should be removed from the skull and rinse tissue quickly in double-distilled to remove blood from the surface. The brain transferred into the impregnation solution made by mixing equal volumes of Solutions A and B, and store at room temperature for 2 weeks in the dark. Add at least $5 \mathrm{ml}$ of the impregnation solution for each brain. Replace the impregnation solution after the first $6 \mathrm{~h}$ of immersion or the next day. Transfer brain tissue into Solution $C$ and store it at room temperature of dark for at least $72 \mathrm{~h}$. Replace the solution at least once after $24 \mathrm{~h}$ of immersion. $80-100 \mu \mathrm{m}$ section can be best cut on a cryostat at $-25^{\circ} \mathrm{C}$ to $-27^{\circ} \mathrm{C}$. Brain tissue may also be mounted with any type of tissue freezing medium, such as OCT. Each section should then be transferred with a glass specimen retriever into a $50 \mathrm{~mL}$ beaker, the beaker outside coated with aluminum foil, which installed Milli-Q water. The beaker should be stirred gently for the first time, then store at room temperature for a few minutes. Place sections in a mixture consisting of 1 part Solution D, 1 part Solution E and 2 parts double-distilled water for $10 \mathrm{~min}$. Rinse sections in double-distilled water 2 times, 4 minutes each. Dehydrate sections in 50\%, 75\%, and 95\% ethanol, $4 \mathrm{~min}$ and $5 \mathrm{~mL}$ each. Dehydrate sections in absolute ethanol, four times, $4 \mathrm{~min}$ and $5 \mathrm{~mL}$ each. The images were obtained by Olympus, FSX100.

\section{Statistics analysis}

Statistical analysis was done by the GraphPad Prism version 6.0 (GraphPad Software). All statistical analyses are presented as mean \pm SEM and were analyzed by twotailed Student's $t$ test and one-way ANOVA including Golgi staining, mEPSCs and WB. Values of $p<0.05$ were considered statistically significant. Statistical significance was set at $" p<0.05,{ }^{* *} p<0.01$, and ${ }^{* * * *} p<0.001$.

\begin{abstract}
Author details
${ }^{1}$ School of Life Sciences, Nanchang University, Nanchang 330031, China. ${ }^{2}$ Institute of Life Science, Nanchang University, Nanchang 330031, China. ${ }^{3}$ School of Basic Medical Sciences, Nanchang University, Nanchang 330031, China. ${ }^{4}$ Key Laboratory of Brain Functional Genomics, Ministry of Education and Shanghai, School of Life Science, East China Normal University, Shanghai 200062, China. ${ }^{5}$ South China Research Center for Acupuncture and Moxibustion, Medical College of Acu-Moxi and Rehabilitation, Guangzhou University of Chinese Medicine, Guangzhou 510006, China
\end{abstract}

\section{Author contributions}

E.F. and P.C. conceived and designed the research project. P.C., H.J., M.X., Q.Z., D.Y., and E.F. performed experiments and collected data. P.C., Q.Z., D.L., D.R., T.Z., D.Y., and E.F. analyzed data. S.W., D.Y., Y.C., B.L., and B.-X.P. provided experimental material and contributed to data analysis and discussion. P.C. and E.F. prepared manuscript figures. E.F., P.C., T.Z., and B.-X.P. wrote the manuscript. All authors provided critical review of results and approved the manuscript.

\section{Funding}

This work was supported by grants from the National Natural Science Foundation of China (31771142 and 81460215 to E.F., 31860268 to T.Z., 31861143033 to D.Y.), grants from Shanghai Key Laboratory of Psychotic Disorders (No. $13 \mathrm{dz2} 260500$ to D.Y.) and grants from State Key Laboratory of Neuroscience (to D.Y.)

\section{Ethics statement}

The authors state that all animal research complied with "Guidelines for the Care and Use of Laboratory Animals" promulgated by Nanchang University, and all experimental procedures were approved by the Medical Laboratory Animal Ethics Committee of Nanchang University.

\section{Conflict of interest}

The authors declare no competing interests.

\section{Publisher's note}

Springer Nature remains neutral with regard to jurisdictional claims in published maps and institutional affiliations.

Supplementary information The online version contains supplementary material available at https://doi.org/10.1038/s41419-021-03687-8.

Received: 18 November 2020 Revised: 30 March 2021 Accepted: 30 March 2021

Published online: 14 April 2021

\section{References}

1. Mei, L. \& Nave, K. A. Neuregulin-ERBB signaling in the nervous system and neuropsychiatric diseases. Neuron 83, 27-49 (2014).

2. Pinkas-Kramarski, R. et al. Brain neurons and glial cells express Neu differentiation factor/heregulin: a survival factor for astrocytes. Proc. Natl Acad. Sci. USA 91, 9387-9391 (1994).

3. Corfas, G., Rosen, K. M., Aratake, H., Krauss, R. \& Fischbach, G. D. Differential expression of Aria Isoforms in the rat-brain. Neuron 14, 103-115 (1995).

4. Lu, H. S. et al. Studies on the structure and function of glycosylated and nonglycosylated neu differentiation factors. Similarities and differences of the alpha and beta isoforms. J. Biol. Chem. 270, 4784-4791 (1995).

5. Chuah, M. I. et al. Glial growth factor 2 induces proliferation and structural changes in ensheathing cells. Brain Res. 857, 265-274 (2000).

6. Flames, $\mathrm{N}$. et al. Short- and long-range attraction of cortical GABAergic interneurons by neuregulin-1. Neuron 44, 251-261 (2004).

7. Fazzari, P. et al. Control of cortical GABA circuitry development by Nrg1 and ErbB4 signalling. Nature 464, 1376-1380 (2010).

8. Ting, A. K. et al. Neuregulin 1 promotes excitatory synapse development and function in GABAergic interneurons. J. Neurosci. 31, 15-25 (2011).

9. Del Pino, I. et al. Erbb4 deletion from fast-spiking interneurons causes schizophrenia-like phenotypes. Neuron 79, 1152-1168 (2013). 
10. Yin, D. M. et al. Reversal of behavioral deficits and synaptic dysfunction in mice overexpressing neuregulin 1. Neuron 78, 644-657 (2013).

11. Huang, Y. Z. et al. Regulation of neuregulin signaling by PSD-95 interacting with ErbB4 at CNS synapses. Neuron 26, 443-455 (2000).

12. Buonanno, A. The neuregulin signaling pathway and schizophrenia: from genes to synapses and neural circuits. Brain Res. Bull. 83, 122-131 (2010).

13. Bean, J. C. et al. Genetic labeling reveals novel cellular targets of schizophrenia susceptibility gene: distribution of GABA and non-GABA ErbB4-positive cells in adult mouse brain. J. Neurosci. 34, 13549-13566 (2014).

14. Barros, C. S. et al. Impaired maturation of dendritic spines without disorganization of cortical cell layers in mice lacking NRG1/ErbB signaling in the central nervous system. Proc. Natl Acad. Sci. USA 106, 4507-4512 (2009).

15. Marenco, S. et al. Genetic association of ErbB4 and human cortical GABA levels in vivo. J. Neurosci. 31, 11628-11632 (2011).

16. Luykx, J. J. et al. A common variant in ERBB4 regulates GABA concentrations in human cerebrospinal fluid. Neuropsychopharmacology 37, 2088-2092 (2012).

17. Howard, D. M. et al. Genome-wide meta-analysis of depression identifies 102 independent variants and highlights the importance of the prefrontal brain regions. Nat. Neurosci. 22, 343-352 (2019).

18. Schork, A. J. et al. A genome-wide association study of shared risk across psychiatric disorders implicates gene regulation during fetal neurodevelopment. Nat. Neurosci. 22, 353-361 (2019).

19. Yang, J. Z. et al. Association study of neuregulin 1 gene with schizophrenia Mol. Psychiatry 8, 706-709 (2003).

20. Walsh, T. et al. Rare structural variants disrupt multiple genes in neurodevelopmental pathways in schizophrenia. Science 320, 539-543 (2008).

21. Stefansson, $\mathrm{H}$. et al. Neuregulin 1 and susceptibility to schizophrenia. Am. J. Hum. Genet. 71, 877-892 (2002).

22. Nicodemus, K. K. et al. Biological validation of increased schizophrenia risk with NRG1, ERBB4, and AKT1 epistasis via functional neuroimaging in healthy controls. Arch. Gen. Psychiatry 67, 991-1001 (2010).

23. Shi, J. et al. Common variants on chromosome 6 p22.1 are associated with schizophrenia. Nature 460, 753-757 (2009).

24. Li, D., Collier, D. A. \& He, L. Meta-analysis shows strong positive association of the neuregulin 1 (NRG1) gene with schizophrenia. Hum. Mol. Genet. 15 1995-2002 (2006).

25. Mostaid, M. S. et al. Meta-analysis reveals associations between genetic variation in the $5^{\prime}$ and $3^{\prime}$ regions of Neuregulin-1 and schizophrenia. Transl. Psychiatry 7, e1004 (2017).

26. Schizophrenia Working Group of the Psychiatric Genomics C. Biological insights from 108 schizophrenia-associated genetic loci. Nature 511, 421-427 (2014).

27. Law, A. J. et al. Neuregulin 1 transcripts are differentially expressed in schizophrenia and regulated by $5^{\prime}$ SNPs associated with the disease. Proc. Natl Acad. Sci. USA 103, 6747-6752 (2006)

28. Hashimoto, R. et al. Expression analysis of neuregulin-1 in the dorsolateral prefrontal cortex in schizophrenia. Mol. Psychiatry 9, 299-307 (2004).

29. Parlapani, E. et al. Gene expression of neuregulin-1 isoforms in different brain regions of elderly schizophrenia patients. World J. Biol. Psychiatry 11, 243-250 (2010).

30. Moon, E. et al. Lack of association to a NRG1 missense polymorphism in schizophrenia or bipolar disorder in a Costa Rican population. Schizophr. Res. 131, 52-57 (2011).

31. Wang, R. et al. Decreased plasma levels of neureglin-1 in drug naive patients and chronic patients with schizophrenia. Neurosci. Lett. 606, 220-224 (2015).

32. Chung, D. W. et al. Dysregulated ErbB4 splicing in schizophrenia: selective effects on parvalbumin expression. Am. J. Psychiatry 173, 60-68 (2016).

33. Brennand, K. J. \& Gage, F. H. Modeling psychiatric disorders through reprogramming. Dis. Models Mech. 5, 26-32 (2012).

34. Hahn, C. G. et al. Altered neuregulin 1-erbB4 signaling contributes to NMDA receptor hypofunction in schizophrenia. Nat. Med. 12, 824-828 (2006).

35. Mahar, I. et al. Disrupted hippocampal neuregulin-1/ErbB3 signaling and dentate gyrus granule cell alterations in suicide. Transl. Psychiatry 7, e1161 (2017).

36. Belzeaux, R. et al. Clinical variations modulate patterns of gene expression and define blood biomarkers in major depression. J. Psychiatr. Res. 44, 1205-1213 (2010).

37. Dang, R. et al. Dysregulation of Neuregulin-1/ErbB signaling in the prefrontal cortex and hippocampus of rats exposed to chronic unpredictable mild stress. Physiol. Behav. 154, 145-150 (2016).

38. Deakin, I. H. et al. Behavioural characterization of neuregulin 1 type I overexpressing transgenic mice. Neuroreport 20, 1523-1528 (2009).
39. Deakin, I. H. et al. Transgenic overexpression of the type I isoform of neuregulin 1 affects working memory and hippocampal oscillations but not longterm potentiation. Cereb. Cortex 22, 1520-1529 (2012).

40. Chen, Y. J. et al. Type III neuregulin-1 is required for normal sensorimotor gating, memory-related behaviors, and corticostriatal circuit components. J. Neurosci. 28, 6872-6883 (2008).

41. Kato, T. et al. Phenotypic characterization of transgenic mice overexpressing neuregulin-1. PLOS ONE 5, e14185 (2010).

42. Preston, A. R. \& Eichenbaum, H. Interplay of hippocampus and prefrontal cortex in memory. Curr. Biol. 23, R764-R773 (2013).

43. Mayford, M. et al. Control of memory formation through regulated expression of a CaMKII transgene. Science 274, 1678-1683 (1996).

44. Sarmiere, P. D. \& Bamburg, J. R. Head, neck, and spines: a role for LIMK-1 in the hippocampus. Neuron 35, 3-5 (2002)

45. Meng, Y. H. et al. Abnormal spine morphology and enhanced LTP in LIMK-1 knockout mice. Neuron 35, 121-133 (2002).

46. Yang, N. et al. Cofilin phosphorylation by LIM-kinase 1 and its role in Racmediated actin reorganization. Nature 393, 809-812 (1998).

47. Bernstein, B. W. \& Bamburg, J. R. ADF/cofilin: a functional node in cell biology. Trends Cell Biol. 20, 187-195 (2010).

48. Wang, J. Y., Miller, S. J. \& Falls, D. L. The N-terminal region of neuregulin isoforms determines the accumulation of cell surface and released neuregulin ectodomain. J. Biol. Chem. 276, 2841-2851 (2001).

49. Ohashi, $K$. et al. Damnacanthal, an effective inhibitor of LIM-kinase, inhibits cell migration and invasion. Mol. Biol. Cell 25, 828-840 (2014).

50. Matus, A., Ackermann, M., Pehling, G., Byers, H. R. \& Fujiwara, K. High actin concentrations in brain dendritic spines and postsynaptic densities. Proc. Natl Acad. Sci. USA 79, 7590-7594 (1982).

51. Star, E. N., Kwiatkowski, D. J. \& Murthy, V. N. Rapid turnover of actin in dendritic spines and its regulation by activity. Nat. Neurosci. 5, 239-246 (2002).

52. Oh, Y. \& Waxman, S. G. The beta 1 subunit mRNA of the rat brain $\mathrm{Na}+$ channel is expressed in glial cells. Proc. Natl Acad. Sci. USA 91, 9985-9989 (1994).

53. Tashiro, A., Minden, A. \& Yuste, R. Regulation of dendritic spine morphology by the rho family of small GTPases: antagonistic roles of Rac and Rho. Cereb. Cortex 10, 927-938 (2000).

54. Tan, A. M., Chang, Y. W., Zhao, P., Hains, B. C. \& Waxman, S. G. Rac1-regulated dendritic spine remodeling contributes to neuropathic pain after peripheral nerve injury. Exp. Neurol. 232, 222-233 (2011).

55. Govek, E. E. et al. The X-linked mental retardation protein oligophrenin-1 is required for dendritic spine morphogenesis. Nat. Neurosci. 7, 364-372 (2004).

56. Zhang, H., Webb, D. J., Asmussen, H., Niu, S. \& Horwitz, A. F. A GIT1/PIX/Rac/ PAK signaling module regulates spine morphogenesis and synapse formation through MLC. J. Neurosci. 25, 3379-3388 (2005).

57. Machesky, L. M. et al. Scar, a WASp-related protein, activates nucleation of actin filaments by the Arp2/3 complex. Proc. Natl Acad. Sci. USA 96, 3739-3744 (1999).

58. Miki, H., Sasaki, T., Takai, Y. \& Takenawa, T. Induction of filopodium formation by a WASP-related actin-depolymerizing protein N-WASP. Nature 391, 93-96 (1998).

59. Schratt, G. M. et al. A brain-specific microRNA regulates dendritic spine development. Nature 439, 283-289 (2006).

60. Wang, J. Y., Frenzel, K. E., Wen, D. \& Falls, D. L. Transmembrane neuregulins interact with LIM kinase 1, a cytoplasmic protein kinase implicated in development of visuospatial cognition. J. Biol. Chem. 273, 20525-20534 (1998).

61. Sigler, A. et al. Formation and maintenance of functional spines in the absence of presynaptic glutamate release. Neuron 94, 304-311 (2017). e304.

62. Garey, L. J. et al. Reduced dendritic spine density on cerebral cortical pyramidal neurons in schizophrenia. J. Neurol. Neurosurg. Psychiatry 65, 446-453 (1998).

63. Glantz, L. A. \& Lewis, D. A. Decreased dendritic spine density on prefrontal cortical pyramidal neurons in schizophrenia. Arch. Gen. Psychiatry 57, 65-73 (2000).

64. Moyer, C. E., Shelton, M. A. \& Sweet, R. A. Dendritic spine alterations in schizophrenia. Neurosci. Lett. 601, 46-53 (2015).

65. Kolluri, N., Sun, Z., Sampson, A. R. \& Lewis, D. A. Lamina-specific reductions in dendritic spine density in the prefrontal cortex of subjects with schizophrenia. Am. J. Psychiatry 162, 1200-1202 (2005).

66. Kolomeets, N. S., Orlovskaya, D. D., Rachmanova, V. I. \& Uranova, N. A. Ultrastructural alterations in hippocampal mossy fiber synapses in schizophrenia: a postmortem morphometric study. Synapse 57, 47-55 (2005).

67. Papaleo, F. et al. Behavioral, neurophysiological, and synaptic impairment in a transgenic Neuregulin1 (NRG1-IV) murine schizophrenia model. J. Neurosci. 36 4859-4875 (2016). 
68. Feng, G. et al. Imaging neuronal subsets in transgenic mice expressing multiple spectral variants of GFP. Neuron 28, 41-51 (2000).

69. Petryshen, T. L. et al. Support for involvement of neuregulin 1 in schizophrenia pathophysiology. Mol. Psychiatry 10, 366-374 (2005). 328.

70. Chong, V. Z. et al. Elevated neuregulin-1 and ErbB4 protein in the prefrontal cortex of schizophrenic patients. Schizophr. Res 100, 270-280 (2008).

71. Wang, W. et al. The protective role of Neuregulin1-ErbB4 signaling in a chronic social defeat stress model. Neuroreport 31, 678-685 (2020).

72. $\mathrm{Xu}$, J. et al. Nedd4l downregulation of NRG1 in the MPFC induces depressionlike behaviour in CSDS mice. Transl. Psychiatry 10, 249 (2020).

73. Gao, T. T. et al. LIMK1/2 in the mPFC plays a role in chronic stress-induced depressive-like effects in mice. Int. J. Neuropsychopharmacol. 23, 821-836 (2020).
74. Kang, $H$. J. et al. Decreased expression of synapse-related genes and loss of synapses in major depressive disorder. Nat. Med. 18, 1413-1417 (2012).

75. Lai, K. O. et al. TrkB phosphorylation by Cdk5 is required for activity-dependent structural plasticity and spatial memory. Nat. Neurosci. 15, 1506-1515 (2012).

76. Wang, Y. N. et al. Controlling of glutamate release by neuregulin3 via inhibiting the assembly of the SNARE complex. Proc. Natl Acad. Sci. USA 115 2508-2513 (2018).

77. Li, M. Y. et al. A critical role of presynaptic cadherin/catenin/p140Cap complexes in stabilizing spines and functional synapses in the neocortex. Neuron 94, 1155-1172 (2017). e1158.

78. Yin, D. M. et al. Regulation of spine formation by ErbB4 in PV-positive interneurons. J. Neurosci. 33, 19295-19303 (2013). 